ПРАВОВАЯ ЖИЗНЬ:

НАУЧНО-ПРАКТИЧЕСКИЕ ЗАКЛЮЧЕНИЯ, КОММЕНТАРИИ И ОБЗОРЫ

UDC 340.155.2(47)

\author{
I. A. Vasiliev, M. U. Aroyan
}

\title{
THE MAIN ISSUES ON PAYING THE TRAINING COMPENSATION IN FIFA DISPUTE RESOLUTION CHAMBER'S CASES 2015
}

The Training Compensation Mechanism was established by the FIFA as a decision regarding financial balance between football clubs in cases of transfer of players. Training Compensation has an obligatory character and clubs should pay it under two conditions which are exclusively concerned with transfers and are set out in Regulations on the Status and Transfer of Players, particularly, in Article 20 and in Annex 4 of these Regulations. In spite of clearly, transparent provisions, football clubs often tend not to pay compensation and appeal to the disproportional amount of training compensation. In the present article the authors analyze case law of the FIFA Dispute Resolution Chamber (JanuaryDecember 2015) and engage in a comparative review that determines the clubs' weakest arguments, and why a few of clubs arguments were approved by the Chamber. Refs 5 .

Keywords: training compensation, players transfers, players' loan, Dispute Resolution Chamber.

\section{The system of training compensation currently provided for by the FIFA Regulations was established to serve the reality of the professional men's football only?}

DRC pointed out that the current training compensation system was created considering the reality of the men's eleven-a-side football only ${ }^{1}$. Indeed, the current training costs used for calculating the training compensation were established after a large and complete study of the relevant figures of the men's eleven-a-side football. Moreover, the DRC recalled that the training compensation amounts were determined within the scope of an extensive process initiated by FIFA with the participation of all stakeholders and constituted a response to the needs of men's football after the challenge by the European

Vasiliev Ilyia A. - Candidate of Law Sciences, Associate Professor, St. Petersburg State University, 7-9, Universitetskaya nab., St. Petersburg, 199034, Russian Federation; i.vasilev@spbu.ru

Aroyan Mariam U. - Independent Researcher, Russian Federation; aroyanmmm789@gmail.com

${ }^{1}$ Decision of the Dispute Resolution Chamber passed in Zurich, Switzerland, on 5 November 2015 (11150999-e). URL: http://www.fifa.com/about-fifa/official-documents/governance/dispute-resolutionchamber.html (accessed: 18.07.2017).

(c) Санкт-Петербургский государственный университет, 2017 
Commission of the international transfer system in place. Bearing in mind the above, the DRC concurred that, although there has been progress, the reality of women's football still significantly differs from that of the men's eleven-a-side game. The budgets, expenses and costs currently involved in each are certainly not comparable.

Therefore, after considering all the mentioned factors, the DRC agreed that the existing training compensation system, as such, at least for the time being, cannot be applied to women's football that shows a scenario completely diverse from the men's eleven-a-side football ${ }^{2}$. In fact, while recognizing the Club-Claimant's arguments that the women's game has undisputedly made important progresses in recent times and its development is in constant raise, the grade of professionalism in women's football is still to be qualified as being at its beginnings. Only few associations have already clubs affiliated to them whose teams engage professional female players.

In this respect, the DRC deemed it appropriate to stress that the system of training compensation currently provided for by the FIFA Regulations was established to serve the reality of the professional men's football, however, not to be applied in an environment like the current still in a developing phase status of the women's game. In order to corroborate this statement, the DRC referred once again to the situation with regard to training compensation for futsal players. In this regard, the members made reference to Annexe 6, art. 9 of the FIFA Regulations, that establishes that «the provisions on training compensation, as provided for in art. 20 and Annex 4 of the Regulations for the Status and Transfer of Players shall not apply to the transfer of players to and from futsal clubs».

Considering such provision, the DRC proceeded to analyze the reasoning of the inapplicability of the training compensation for futsal players. First and foremost, it considered that the reality of the futsal is undisputedly different from the men's eleven-a-side football, which would per se justify the established exception. In this regard, the DRC members held that futsal is developed only in certain regions and had not yet reached a consistent global coverage. Additionally, the grade of professionalism reached in futsal also lies far behind the one of eleven-a-side football. Insofar, according to the DRC, the situation may be considered as comparable to the one of the women's game.

The DRC, therefore, concluded that, contrary to the Claimant's opinion, the current structure of the women's football shows that the women's football has also not yet achieved a highly developed grade of professionalism and, in analogy with the futsal clubs, the particularities of the women's game must be considered while applying the Regulations. In this respect, the DRC reiterated that the training compensation claim of the Claimant is inadmissible.

\section{Respondent's position as a renouncing its right of defense?}

Dispute Resolution Chamber (hereinafter - DRC) practices on issue are generally depends on the right of defense used by the Respondent. In cases on training compensation the Respondent may not reply to the claim and therefore renounced its right of defense. This means that the Club-Respondent does not provide any argument which justifies the non-payment of training compensation to the Club-Claimant. DRC notes that

${ }^{2}$ Decision of the Dispute Resolution Chamber passed in Zurich, Switzerland, on 5 November 2015 (11150999-e). URL: http://www.fifa.com/about-fifa/official-documents/governance/dispute-resolutionchamber.html (accessed: 18.07.2017). 
Respondent may never took position in the claim or had not replied to the claim of the Claimant, although having been invited to do so by FIFA DRC ${ }^{3}$.

\section{Player was re-registered as a professional?}

DRC stipulates that if the player re-register as a professional within 30 months of being reinstated as an amateur after transfer, his new club shall, in principle, pay training compensation (referred to art. 3 par. 2 sent. 2 of the FIFA Regulations). In view of the above, the DRC concurred that a player was re-registered as a professional with the ClubRespondent after a period of 20 months and within 30 months of being reinstated as an amateur ${ }^{4}$. So, the Respondent shall pay training compensation in accordance with art. 20 of the FIFA Regulations (subsequent transfer).

\section{When transfer of the player from the club from country A to the club from country B has to be considered as a subsequent transfer of a professional player, and, therefore, only the previous club of the player would be entitled to receive training compensation?}

Club-Respondent assessed that a transfer agreement is concluded whenever a club wants to register a player who is currently registered with another club, and whose employment contract with said club is valid 5 . In this respect, the Respondent held that it had paid EUR 100,000 to the involved club in order to release the player, thus, the Respondent concluded the player was not an amateur. In particular, the Respondent referred to the Court of Arbitration for Sport (hereinafter - CAS) jurisprudence, according to which, "the amateur status can also be corroborated by the fact that it is only because the Player was amateur that he was able to leave his previous club to join another club, without being hindered from being engaged in other professional activities or occupations» ${ }^{6}$. In light of

${ }^{3}$ Decision of the Dispute Resolution Chamber passed in Zurich, Switzerland, on 21 May 2015 (0515256). URL: http://www.fifa.com/about-fifa/official-documents/governance/dispute-resolution-chamber.html (accessed: 18.07.2017); Decision of the Dispute Resolution Chamber passed in Zurich, Switzerland, on 12 May 2015 (0515271). URL: http://www.fifa.com/about-fifa/official-documents/governance/disputeresolution-chamber.html (accessed: 18.07.2017); Decision of the Dispute Resolution Chamber passed in Zurich, Switzerland, on 2 July 2015 (07152149_english). URL: http://www.fifa.com/about-fifa/official-documents/governance/dispute-resolution-chamber.html (accessed: 18.07.2017); Decision of the Dispute Resolution Chamber passed in Zurich, Switzerland, on 26 November 2015 (1115706). URL: http://www.fifa.com/ about-fifa/official-documents/governance/dispute-resolution-chamber.html (accessed: 18.07.2017); Decision of the Dispute Resolution Chamber passed in Zurich, Switzerland, on 26 November 2015 (11151600e). URL: http://www.fifa.com/about-fifa/official-documents/governance/dispute-resolution-chamber.html (accessed: 18.07.2017); Decision of the Dispute Resolution Chamber passed in Zurich, Switzerland, on 3 September 2015 (0915513). URL: http://www.fifa.com/about-fifa/official-documents/governance/dispute-resolution-chamber.html (accessed: 18.07.2017).

${ }^{4}$ Decision of the Dispute Resolution Chamber passed in Zurich, Switzerland, on 12 May 2015 (0515271). URL: http://www.fifa.com/about-fifa/official-documents/governance/dispute-resolution-chamber.html (accessed: 18.07.2017).

${ }^{5}$ Decision of the Dispute Resolution Chamber passed in Zurich, Switzerland, on 5 November 2015 (11152758-e). URL: http://www.fifa.com/about-fifa/official-documents/governance/dispute-resolutionchamber.html (accessed: 18.07.2017).

${ }^{6}$ Arbitration CAS 2006/A/1027 Blackpool F.C. v. Club Topp Oss, award of 13 July 2006. URL: http:// jurisprudence.tas-cas.org/Search/results.aspx k=Title\%3D'508A151D-795A-4840-A64D-4907061DA103' (accessed: 18.07.2017). 
the foregoing, the Respondent concluded that the player had entered into a contract with the involved club and that he was bound by said contract, thus, he was already a professional player before being transferred to the Respondent. Consequently, the Respondent requested the rejection of the claim.

Upon request, Football Association of country $\mathrm{H}$ and the involved club confirmed to TMS Compliance, in the context of their investigation on the subject, that on 24 June 2011 the Football Association of country $\mathrm{H}$ informed the Football Association of country B that the player was going to be registered as an amateur. Furthermore, the Football Association of country H held that «after 17 July 2011, Football Association of country H had no any kind of connection with this transfer or with the aforementioned player, because the jurisdiction for the registration of the player was on Regional Registration Body in the City J. After we checked it, we can confirm that the Player E has been registered as the member of [the involved club] in amateur status since 20 July $2011(\ldots)$. We can confirm that we have no knowledge of the existence of any employment contract between the club and the player ${ }^{7}$. Equally, DRC considered that the Football Association of country $\mathrm{H}$ confirmed that the player had been registered as an amateur with the involved club.

Subsequently, the DRC referred to the general legal principle of the burden of proof, which is a basic principle in every legal system, according to which a party deriving a right from an asserted fact has the obligation to prove the relevant fact (cf. art. 12 par. 3 of the FIFA Procedural Rules). In this respect, the DRC turned its attention to the rare evidence on file and considered the relevant transfer agreement as the most convincing element. According to said agreement, the involved club and the Respondent had agreed upon a transfer compensation amounting to EUR 100,000. Said payment, so the DRC, symbolizes the amount payable to the former club in order to enable the transfer of a player to a new club during the validity of his employment contract. Consequently, the DRC concluded that transfer compensation would clearly speak for a professional status of the player with his previous club.

Taking into account the above and due to the lack of proof with regard to the amateur status of the player with the involved club, the DRC did not uphold the Club-Claimant's position. In light of the above, the DRC concluded that the Claimant is not entitled to receive training compensation from the Respondent since the transfer of the player from the club from country A to the club from country B has to be considered as a subsequent transfer of a professional player, and, therefore, only the previous club of the player would be entitled to receive training compensation.

\section{Who could make a waiver regarding training compensation?}

In this question, the DRC referred to art. 12 par. 3 of the FIFA Procedural Rules, which essentially stipulates that any party claiming a right on the basis of an alleged fact shall carry the burden of proof. Respondent shall proof that the Claimant had waived its right to claim training compensation. DRC stressed that a waiver regarding training compensation could only possibly made by the club which is entitled to training compensa-

${ }^{7}$ Decision of the Dispute Resolution Chamber passed in Zurich, Switzerland, on 5 November 2015 (11152758-e). URL: http://www.fifa.com/about-fifa/official-documents/governance/dispute-resolutionchamber.html (accessed: 18.07.2017). 
tion $^{8}$. So, Club-Respondent could not rely on such statement or has to provide any proof in this regard. Respondent, at no point, provided any proof for its assumption that it could register the player without the obligation to pay training compensation to any third club. Its argument that the player had «zero market price» has no influence on the Respondent's obligation to pay training compensation. In this issue we agree with Jonh Shea, had early stated as follows «... a declaration by a club to the effect that a player has been granted a free transfer is also not sufficient to waive the right to claim training compensation» [1].

\section{The consequences when player's agent, at the moment of the signature of the employment contract, ensured that he had not received an offer to enter into a contract with the Club-Claimant?}

DRC emphasized that, in accordance with art. 6 par. 3 sent. 1 of Annexe 4 of the Regulations, if the former club does not offer the player a contract, no training compensation is payable unless the former club can justify that it is entitled to such compensation ${ }^{9}$. The former club must offer the player a contract in writing via registered mail at least 60 days before the expiry of his current contract (cf. art. 6 par. 3 sent. 2 of Annexe 4 of the FIFA Regulations). DRC referred to art. 12 par. 3 of the Procedural Rules, which stipulates that any party claiming a right on the basis of an alleged fact shall carry the burden of proof, and, in this respect, pointed out that the Club-Claimant had not made any efforts to justify that it would be entitled to training compensation in accordance with art. 6 par. 3 sent. 1 in fine of Annexe 4 of the Regulations (which, according to the well-established jurisprudence of the DRC, is limited to very exceptional circumstances). In this respect, it is important to underline that the Club-Claimant had not brought forward the occurrence of a very exceptional circumstance which, in the case at hand, had stopped the Claimant from offering the player a contract. So DRC had no reason to believe that very exceptional circumstances had prevented the Claimant from offering the player a contract 60 days before the expiry of his employment contract. In view of the foregoing, the DRC determined that the Claimant is not entitled to receive training compensation from the Respondent for the training and education of the player.

\section{International transfer needs to be entered in TMS whenever a player is to be registered as a professional by the new association?}

DRC was eager to point out that the Club-Respondent had acknowledged that it had carried out the transfer of the player via the Transfer Matching System (TMS) and that it registered the player as a professional. Taking into account the foregoing, we could referred to art. 1 par. 6 of Annexe 3 of the FIFA Regulations, which stipulates that an international transfer needs to be entered in TMS whenever a player is to be registered as a professional by the new association. At this point, the DRC judge wished to emphasize that there was

${ }^{8}$ Decision of the Dispute Resolution Chamber passed in Zurich, Switzerland, on 12 May 2015 (0515359-e). URL: http://www.fifa.com/about-fifa/official-documents/governance/dispute-resolutionchamber.html (accessed: 18.07.2017).

9 Decision of the Dispute Resolution Chamber passed in Zurich, Switzerland, on 12 May 2015 (05150533-e). URL: http://www.fifa.com/about-fifa/official-documents/governance/dispute-resolutionchamber.html (accessed: 18.07.2017). 
no need for the Respondent to enter the transfer of the player in TMS if the player was not to be registered a professional ${ }^{10}$. However, the Respondent entered the transfer of the player in TMS and, in addition, acknowledged that the player was actually registered as a professional. Consequently, the DRC concluded that it could indeed be established that the player obtained the professional status upon his registration with the Respondent.

\section{What evidences are obligatory to DRC in amount of training compensation if it is clearly disproportionate?}

Dispute Resolution Chamber recalled that, according to art. 5 par. 4 of Annexe 4 of the FIFA Regulations, the DRC may review disputes concerning the amount of training compensation payable and shall have discretion to adjust this amount if it is clearly disproportionate to the case under review. In this regard, we have to eager to emphasise that such possibility allowed by the FIFA Regulations would, in any case, have to be analysed on a case-by-case basis ${ }^{11}$. In the present case ${ }^{12}$, the Club-Respondent held that the costs that it would have incurred per season if it had trained the player itself are approximately based on the «academy costs - youth football player» in the club's financial statement of the 2006-07 season and the number of registered players in said academy for the same season. The DRC, however, considered that the documents presented by the Respondent in this regard do not constitute objective and convincing evidence that the amount of training compensation is to be considered clearly disproportionate in the matter at hand.

In the similar context, the DRC underlined that the Club-Respondent had not substantiated its request with any pertinent documentary evidence in accordance with art. 12 par. 3 of the FIFA Procedural Rules, which stipulates that any party claiming a right on the basis of an alleged fact shall carry the burden of proof. In fact, the Respondent merely alleged that its income decreased significantly in the 2014/2015 due to its relegation to a lower league. In this respect, the DRC was eager to point out that the player was registered with the Respondent during the 2013/2014 season, and that, therefore, the obligation to pay training compensation arose during the 2013/2014 season and not during the $2014 / 2015$ season $^{13}$. On account of these considerations and in the absence of any well-founded arguments and documentation in support of the Respondent's request to adjust the amount the DRC had no alternative but to decide that the amount of training compensation payable by the Respondent to the Claimant could not be adjusted.

${ }^{10}$ Decision of the Dispute Resolution Chamber passed in Zurich, Switzerland, on 12 May 2015 (05151596-e). URL: http://www.fifa.com/about-fifa/official-documents/governance/dispute-resolutionchamber.html (accessed: 18.07.2017).

${ }^{11}$ Decision of the Dispute Resolution Chamber passed in Zurich, Switzerland, on 23 July 2015 (07150005_english). URL: http://www.fifa.com/about-fifa/official-documents/governance/dispute-resolution-chamber.html (accessed: 18.07.2017); Decision of the Dispute Resolution Chamber passed in Zurich, Switzerland, on 17 December 2015 (12150933-e). URL: http://www.fifa.com/about-fifa/official-documents/ governance/dispute-resolution-chamber.html (accessed: 18.07.2017).

12 Decision of the Dispute Resolution Chamber passed in Zurich, Switzerland, on 23 July 2015 (07150005_english). URL: http://www.fifa.com/about-fifa/official-documents/governance/dispute-resolution-chamber.html (accessed: 18.07.2017).

${ }^{13}$ Decision of the Dispute Resolution Chamber passed in Zurich, Switzerland, on 17 December 2015 (12150933-e). URL: http://www.fifa.com/about-fifa/official-documents/governance/dispute-resolutionchamber.html (accessed: 18.07.2017). 
In particular case ${ }^{14}$, the Club-Respondent held that no club would undertake to pay EUR 20,000 per year as remuneration and, on top of that, having to pay more than EUR 70,000 as training compensation, to terminate the contract with the player at the end of the season. The Respondent acknowledged having compensated the player for the expenses incurred in his football activity in the amount of EUR 500 gross per month (i.e. EUR 458.25 net per month) from October to December 2013 and EUR 398, 25 net per month from January until July 2014. In particular, the Respondent pointed out that the total compensation paid to the player amounted to EUR 4,162.25. As a result, the Respondent underscored that the amounts compensated cannot be understood as salary.

In this respect, the DRC firstly deemed it important to establish whether the player held the amateur status or the professional status at the time he was registered with the Respondent. To this end, the DRC examined the employment contract as well as the amateur contract that the parties had submitted in the present proceedings. Equally, the DRC thoroughly analyzed the submission of the parties in this respect and, in particular, the statement of the Respondent. In particular, the DRC duly noted that the Respondent that the player was paid de facto a compensation in the amount of EUR 500 gross per month from October to December 2013 and EUR 398.25 net per month from January until July 2014. Thus, the DRC concluded that, irrespective of the contract at the basis of the relationship between the player and the Respondent, as informed by the latter, the player periodically received from the Respondent a fixed monthly amount regardless of the expenses he indeed incurred in and with no obligation to justify these alleged expenses.

In this context, we could referred to art. 2 par. 2 of the FIFA Regulations, which stipulates that A A professional is a player who has a written contract with a club and is paid more for his footballing activity than the expenses he effectively incurs. All other players are considered to be amateurs». In light of the foregoing and taking into consideration the criteria set out in art. 2 par. 2 of the Regulations as well as the amounts payable to the player, the members of the Chamber unanimously concluded that, in the present case, the player was in fact paid more for his footballing activity than the expenses he effectively incurred. In this regard, the Chamber was eager to emphasize that a player's remuneration as per the criteria set out in art. 2 par. 2 of the FIFA Regulations constitutes the decisive factor in the determination of the status of the player and that the legal nature or the designation of the contract is of no relevance in this regard ${ }^{15}$. This approach has been confirmed by the

14 Decision of the Dispute Resolution Chamber passed in Zurich, Switzerland, on 23 July 2015 (07150005_english). URL: http://www.fifa.com/about-fifa/official-documents/governance/dispute-resolution-chamber.html (accessed: 18.07.2017).

15 Decision of the Dispute Resolution Chamber passed in Zurich, Switzerland, on 23 July 2015 (07150005_english). URL: http://www.fifa.com/about-fifa/official-documents/governance/dispute-resolution-chamber.html (accessed: 18.07.2017); Decision of the Dispute Resolution Chamber passed in Zurich, Switzerland, on 13 August 2015 (08151099a-e). URL: http://www.fifa.com/about-fifa/official-documents/ governance/dispute-resolution-chamber.html (accessed: 18.07.2017); Decision of the Dispute Resolution Chamber passed in Zurich, Switzerland, on 13 August 2015 (08151099b-e). URL: http://www.fifa.com/ about-fifa/official-documents/governance/dispute-resolution-chamber.html (accessed: 18.07.2017); Decision of the Dispute Resolution Chamber passed in Zurich, Switzerland, on 13 August 2015 (08151099c-e). URL: http://www.fifa.com/about-fifa/official-documents/governance/dispute-resolution-chamber.html (accessed: 18.07.2017). 
CAS, whereby the Panel also emphasized that the definition contained in the mentioned provision is the only ground to establish a player's status ${ }^{16}$.

DRC pointed out that according to the said decision the classification of a player made by the association of his club is not decisive to determine the status of a player. Equally, the DRC highlighted that the second element contained in said art. 2 par. 2 of the FIFA Regulations, i.e. the existence of a written contract, is met. On account of all the above, the Chamber concurred that the player was registered as a professional with the Respondent.

\section{Classification of a player made by the National Association of his club is not decisive to determine the status of a player?}

Club-Claimant provided FIFA with a copy of the first page of the alleged «non-professional civil contract» concluded between the player and the Respondent on 15 July 2014 and, subsequently, referred to the jurisprudence according to which, the status indicated by a National Association on registration forms, the denomination of the contract concluded or TMS do not supersede art. 2 par. 2 of the FIFA Regulations on the Status and Transfer of Players.

Taking into consideration the criteria set out in art. 2 par. 2 of the Regulations as well as the amounts payable to the player on the basis of the aforementioned contract, the DRC concluded that it was beyond a doubt that the player was in fact paid more for his footballing activity than the expenses he effectively incurred. In this regard, the DRC judge was eager to emphasize that a player's remuneration as per the criteria set out in art. 2 par. 2 of the Regulations constitutes the decisive factor in the determination of the status of the player and that the legal nature or the designation of the contract is of no relevance in this regard ${ }^{17}$. This approach has been confirmed by the CAS in its decision 2006/A/1177 ${ }^{18}$, whereby the Panel also emphasized that the definition contained in the mentioned provision is the only ground to establish a player's status. For the sake of completeness, the DRC judge pointed out that according to the said decision the classification of a player made by the association of his club is not decisive to determine the status of a player.

In view of the above, the DRC concluded that on the basis of the documentation at his disposal that the professional player in question, born on 26 January 1990, was transferred to the Respondent on 25 January 2011, i.e. before the season of the player's $23^{\text {rd }}$ birthday, and thus irrespective of whether the player and the Respondent had or not prematurely terminated their employment contract or whether he was loaned from Club C to Club F Once, the Claimant is entitled to receive training compensation from the Respondent.

16 Arbitration CAS 2009/A/1781 FK Siad Most v. Clube Esportivo Bento Gonçalves, award of 12 October 2009; Arbitration CAS 2006/A/1027 Blackpool F.C. v. Club Topp Oss, award of 13 July 2006.

17 Decision of the Dispute Resolution Chamber passed in Zurich, Switzerland, on 13 August 2015 (08151099a-e). URL: http://www.fifa.com/about-fifa/official-documents/governance/dispute-resolutionchamber.html (accessed: 18.07.2017).

18 Arbitration CAS 2006/A/1177 Aston Villa FC v. B.93 Copenhagen, award of 28 May 2007. 


\section{Was player registered with Club-Respondent as a professional or an amateur?}

Further to the above, the Chamber pointed out that the Football Association of country $\mathrm{G}$ had confirmed that the player was never registered with Club $\mathrm{F}$ as a professional or an amateur. The DRC thereafter referred to the player passport provided by the Football Association of country $\mathrm{D}$, which clearly indicated that prior to the registration with the Respondent, the player only held the amateur status and became professional as from his registration with the Club-Respondent. On account of the aforementioned elements, and in the absence of any conclusive evidence from the Respondent to support its allegations, the DRC concluded that the player had always been registered as an amateur prior to his registration with the Respondent, with which he was registered as a professional for the first time ${ }^{19}$.

In a similar case the DRC underscored that the triggering element for the payment of training compensation is the registration of the player and that the contractual link between the player and the club that loans him is irrelevant for this purpose ${ }^{20}$. In other words, the fact that the player was loaned while under a scholarship agreement with Club and that, upon his return to the latter, the parties concluded a new employment contract, is unconnected with the entitlement of the Club-Claimant to receive training compensation from the Club-Respondent in accordance with art. 20 and Annexe 4 of the FIFA Regulations. However, in this regard, the DRC pointed out that, in casu, a possible obligation to offer the player a contract in compliance with art. 6 par. 3 of Annexe 4 of the Regulations would in principle lie with Club F, this is, the club with which the player concluded a professional agreement that was suspended during the loan, and not with the Claimant. As stated in art. 6 par. 3 of Annexe 4 of the FIFA Regulations, said provision is without prejudice to the right of training compensation of the player's previous club or clubs.

\section{Whether or not a club that accepted a professional on loan is entitled to receive training compensation when, after terminating the contract of the loan, the professional returns to his club of origin?}

Problems of player's loan and after that a right to training compensation are often presented in the DRC practices [for e.g. 2]. In this context, the DRC highlighted that the main issue in the present matter is whether or not a club that accepted a professional on loan is entitled to receive training compensation when, after terminating the contract of the loan, the professional returns to his club of origin, and thereafter, is transferred from the club of origin to a club belonging to another association before the end of the season of the player's $23^{\text {rd }}$ birthday. This approach is also in line with the DRC's well-established jurisprudence that all clubs which have in actual fact contributed to the training and education of a player as from the age of 12 are, in principle, entitled to training compensation for the timeframe that the player was effectively trained by them ${ }^{21}$. In other words, the

19 Decision of the Dispute Resolution Chamber passed in Zurich, Switzerland, on 26 November 2015 (11151021-e). URL: http://www.fifa.com/about-fifa/official-documents/governance/dispute-resolutionchamber.html (accessed: 18.07.2017).

20 Decision of the Dispute Resolution Chamber passed in Zurich, Switzerland, on 2 September 2015 (09151608-e). URL: http://www.fifa.com/about-fifa/official-documents/governance/dispute-resolutionchamber.html (accessed: 18.07.2017).

${ }^{21}$ Decision of the Dispute Resolution Chamber passed in Zurich, Switzerland, on 17 December 2015 (12150933-e). URL: http://www.fifa.com/about-fifa/official-documents/governance/dispute-resolutionchamber.html (accessed: 18.07.2017). 
DRC emphasised that the nature of the player's registration with a club claiming training compensation (on a definite or on a temporary basis) is in fact irrelevant with respect to the question as to whether such club would be entitled to receive training compensation for the period of time that the player was effectively trained by that club.

On other case ${ }^{22}$ DRC noted that in accordance with the information contained in TMS, with the clarifications provided by the Football Association of country B and with the loan contracts provided by the Club-Claimant, the player had an employment contract with Club $\mathrm{F}$ and was, during the course of it, transferred on loan to several clubs from country B. In this context, the DRC recalled the contents of art. 10 par. 1 of the FIFA Regulations and, in this respect, it observed that the player was a professional while registered with the involved club and that he was loaned on the basis of three written agreements to a club from country B, subsequently to the Claimant and thereafter to Club $\mathrm{H}$. In this respect, the DRC formed the belief that regardless of what the status of the player was with each of these clubs, the player was under an employment contract with the involved club and, therefore has to be considered as a professional during the whole period.

In light of the above, the DRC concluded that the player's move to Club $\mathrm{H}$ constituted a loan and not a definitive transfer as alleged by the Club-Respondent. Bearing in mind the foregoing, the DRC deemed that the Respondent's interpretation of art. 3 par. 1 sent. 3 of Annexe 4 of the FIFA Regulations would clearly contravene the intention of the legislator of the Regulations according to which all training clubs shall, in principle, be rewarded for their efforts invested in training young players, including those clubs that have accepted a player on a temporary basis.

DRC has no doubt that the obligation to pay training compensation arises in case a player is definitively transferred from one club to another club belonging to a different association, but not when he is temporarily transferred to another club while still being contractually bound to his club of origin (yet, with the effects of the relevant contract being temporarily suspended), such as a loan ${ }^{23}$. Hence, the relevant entitlement can only be claimed towards a new club that acquires the services of a player on a definitive and permanent basis subject to the fulfilment of the prerequisites established in art. 20 and Annexe 4 of the FIFA Regulations. On account of all the above-mentioned considerations, the DRC decided that the Respondent is liable to pay training compensation to the Claimant in accordance with art. 20 and Annexe 4 of the Regulations.

Also the DRC pointed out that the obligation to pay training compensation thus arises in case a player is definitively transferred from one club to another club belonging to a different association, but not when he is temporarily transferred to another club while still being contractually bound to his club of origin (yet, with the effects of the relevant contract being temporarily suspended), such as a loan ${ }^{24}$. Hence, the relevant entitlement can only be claimed towards a new club that acquires the services of a player on a definitive

${ }^{22}$ Decision of the Dispute Resolution Chamber passed in Zurich, Switzerland, on 25 September 2015 (09150080a-e). URL: http://www.fifa.com/about-fifa/official-documents/governance/dispute-resolutionchamber.html (accessed: 18.07.2017).

${ }^{23}$ Decision of the Dispute Resolution Chamber passed in Zurich, Switzerland, on 15 October 2015 (10151224-e). URL: http://www.fifa.com/about-fifa/official-documents/governance/dispute-resolutionchamber.html (accessed: 18.07.2017).

${ }^{24}$ Decision of the Dispute Resolution Chamber passed in Zurich, Switzerland, on 25 September 2015 (0915783-e). URL: http://www.fifa.com/about-fifa/official-documents/governance/dispute-resolutionchamber.html (accessed: 18.07.2017). 
and permanent basis subject to the fulfilment of the prerequisites established in art. 20 and Annexe 4 of the FIFA Regulations. As to the argument of the Respondent that the Claimant is not the former club in the sense of art. 3 par. 1 sent. 3 of Annexe 4 of the Regulations, the Chamber wished to recall that art. 3 par. 1 sent. 3 of Annexe 4 stipulates that «In the case of subsequent transfers of the professional, training compensation will only be owed to his former club for the time he was effectively trained by that club». In this context, the Chamber acknowledged that the Claimant was not the player's former club stricto sensu, however, the Chamber pointed out that, within the framework of loans, the period of time that the player was registered with the involved club and the period of time that the player was registered with the Claimant on loan, should be considered as one entire timeframe. Any other interpretation would lead to the situation in which clubs accepting a player on loan would never be entitled to receive training compensation, even if they contribute to the training and education of players.

\section{Club which transferred the player on a loan basis to another club is entitled to training compensation for the entire period of time during which it effectively trained the player?}

Club-Respondent held that since (1) the player was an amateur with one of the clubs from country B that registered the player on loan, (2) there was no valid loan to said club from country B and (3) the player did not go back to the Club-Claimant after the registration with said club from country B, it is of the opinion that the player was registered on a definitive basis as a «free agent» with the last club from country B with which the player was registered on loan. Alternatively, the Respondent asserted that the transfer of the player from the Claimant to the last club to which he was loaned was a definitive transfer since the Claimant could not call the player back, it did no longer pay his remuneration, the duration of the loan mirrored the remaining part of the player's employment contract with the Claimant and the loan agreement was called «transfer agreement». In this respect, the Respondent provided a confirmation issued by the player stating that he had never entered into an employment contract with the club from country B that registered the player on loan as «amateur».

Hence, the DRC came to the firm conclusion that for the purposes of the provisions of the FIFA Regulations governing training compensation, the loan of a young player from his club of origin to other clubs does not interrupt the ongoing training period of the player and the obligation to pay training compensation arises only in case a player is transferred on a definitive basis, with the effect that, at that moment, the club which transferred the player on a loan basis to another club is entitled to training compensation for the entire period of time during which it effectively trained the player, however, excluding the period of time of the loan ${ }^{25}$.

25 Decision of the Dispute Resolution Chamber passed in Zurich, Switzerland, on 25 September 2015 (09150080c-e). URL: http://www.fifa.com/about-fifa/official-documents/governance/dispute-resolutionchamber.html (accessed: 18.07.2017). 


\section{Whether the Club-Claimant had waived its right to training compensation}

by signing the tripartite agreement with the player and the Club-Respondent?

In continuation, the DRC had to establish, as alleged by the Club-Respondent, as to whether the Club-Claimant had waived its right to training compensation by signing the agreement with the player and the Respondent following the award issued by the CAS in the employment-related dispute between the Claimant, the player and the Respondent ${ }^{26}$. After careful examination of the pertinent elements on file, the members of the Chamber concluded that the Claimant had not waived its right to training compensation by signing the tripartite agreement. What is more, the Dispute Resolution Chamber noted that the DRC decision passed in the employment-related dispute and confirmed by the CAS explicitly excludes training compensation, since training compensation was the object of separate proceedings presently under examination by this Chamber.

\section{Was the player's training already completed at the time the player joined the Club-Respondent?}

The Dispute Resolution Chamber stressed that both the DRC and the CAS have adopted a strict approach in establishing the early completion of the player's training before the age of 21 , so as to not jeopardize the right of training clubs to, in principle, receive training compensation ${ }^{27}$. In this regard, the Chamber noted, once more, all the specific circumstances of the present matter as well as all the evidence produced by the Respondent. The DRC highlighted that the mere facts that the player had been a professional with the Claimant since 2004 on the basis of various employment contracts allegedly earning substantial amounts and allegedly having participated in 15 matches of the Claimant during the 2007 season, do not allow to conclude that the player had already completed his training period before the age of 21 . The DRC agreed that the Respondent club has not sufficiently substantiated its claim that the player's training had already ended before his $21^{\text {st }}$ birthday and concluded, therefore, that this argument cannot be upheld.

\section{Training compensation is not due if the player's former club terminated the player's contract without just cause?}

Art. 2 par. 2 lit. (i) of Annexe 4 of the FIFA Regulations on the Status and Transfer of Players inter alia reads that training compensation is not due if the player's former club terminated the player's contract without just cause. In this regard, the DRC firstly wished to refer to art. 9 par. 1 lit. (e) of the Procedural Rules, which set forth that petitions before FIFA's decision-making bodies shall contain documents of relevance to the dispute, such as contract and previous correspondence with respect to the case in the original version

${ }^{26}$ Decision of the Dispute Resolution Chamber passed in Zurich, Switzerland, on 23 July 2015 (07150005_english). URL: http://www.fifa.com/about-fifa/official-documents/governance/dispute-resolution-chamber.html (accessed: 18.07.2017).

27 Decision of the Dispute Resolution Chamber passed in Zurich, Switzerland, on 23 July 2015 (07150005_english). URL: http://www.fifa.com/about-fifa/official-documents/governance/dispute-resolution-chamber.html (accessed: 18.07.2017). 
and, if applicable, translated into one of the official FIFA languages, i.e. English, French, Spanish or German ${ }^{28}$. Accordingly, the DRC concluded that the document submitted by the Club-Respondent in support of its aforementioned argument, i.e. a copy of a ruling of a court of country B drafted in the language of country B, which was not duly translated into one of the official FIFA languages of FIFA, could not be taken into account in the assessment of the present matter. Thus, bearing in mind the contents of art. 12 par. 3 of the Procedural Rules, in accordance with which a party claiming a right on the basis of an alleged fact shall carry the burden of proof, the DRC held that the Respondent's argument that the Club-Claimant was not entitled to training compensation by application of art. 2 par. 2 (i) of Annexe 4 of the Regulations was not corroborated by any conclusive evidence and must therefore be rejected.

\section{Claimant terminated the player's contract without just cause and waived its right to claim training compensation?}

DRC emphasized that both parties referred to the settlement agreement signed between the Club-Claimant and the player, to substantiate their positions. On one hand, the Claimant referred to said agreement and argued to be entitled to its proportion of training compensation being the player's former club and, on the other hand, the ClubRespondent referred to said agreement to proof that the Claimant terminated the player's contract without just cause and waived its right to claim training compensation and hence is not entitled to any compensation in connection with the player's registration ${ }^{29}$.

Also, the DRC deemed appropriate to underline that neither did the Respondent refer to a particular clause of the agreement nor provide any other piece of evidence to corroborate its argument that Claimant has terminated the employment contract signed with the player without just cause or has waived its entitlement to training compensation. Finally, the DRC noted that anyway said agreement is only legally valid between the player and the Claimant and has no reference to the topic of training compensation. Therefore, the DRC judge concludes that based on the said agreement he cannot establish that the Claimant has waived its right to claim training compensation. The DRC judge finds that the Respondent failed to substantially discharge its burden of proving the alleged (1) unjustified termination of the employment contract by the Claimant and (2) the Claimant's waiver. For all of the above, the DRC holds that the Claimant is entitled to training compensation.

\section{Did the Football Association commit a manifest error of assessment when categorizing the Club-Respondent?}

DRC emphasized that it was the Club-Claimant's responsibility to demonstrate that The Football Association of country D had committed a manifest error of assessment when

${ }^{28}$ Decision of the Dispute Resolution Chamber passed in Zurich, Switzerland, on 3 September 2015 (09151743). URL: http://www.fifa.com/about-fifa/official-documents/governance/dispute-resolutionchamber.html (accessed: 18.07.2017).

29 Decision of the Dispute Resolution Chamber passed in Zurich, Switzerland, on 25 September 2015 (0915783-e). URL: http://www.fifa.com/about-fifa/official-documents/governance/dispute-resolutionchamber.html (accessed: 18.07.2017). 
categorizing the Club-Respondent ${ }^{30}$. In this regard, the DRC recalled the basic principle of the burden of proof, as stipulated in art. 12 par. 3 of the FIFA Procedural Rules, according to which a party claiming a right on the basis of an alleged fact shall carry the respective burden of proof. Having the latter principle in mind, the DRC pointed out that the Claimant did not substantiate its assertions as to the Respondent's participation in the first division of country D as well as in the European competitions with any documentation and thus, held that the Claimant failed to satisfactorily carry the burden of proof regarding the alleged wrong categorization of Respondent. Consequently, the DRC judge concluded that the Respondent was to be considered as a category IV club and that therefore, in accordance with art. 2 par. 2 lit. II. of Annexe 4 of the Regulations, no training compensation is due by the latter in connection with the first registration as a professional of the player.

\section{Can Club-Respondent that relies in good faith on the information contained in a player passport be held liable due to information which appeared in a second player passport?}

Club-Respondent mentioned that it is the responsibility of the association to assure that the information contained in a player passport is correct according to art. 8 par. 1 no. 3 of Annexe 3 and art. 2 no. 3 of Annexe 3a of the Regulations on the Status and Transfer of Players. Further to this, the Respondent stated that according to well-established jurisprudence of the FIFA Dispute Resolution Chamber, a club that relies in good faith on the information contained in a player passport cannot be held liable due to information which appeared in a second player passport ${ }^{31}$. Therefore, the Respondent asserted that it could in good faith trust the information contained in player passport 1 , which was firstly issued and uploaded by the Football Association of country B.

Upon request of the FIFA administration, the Football Association of country B clarified that «Club A (which was later renamed into Club A2) is wholly owned by Club A, which is the sole founder of the Academy and effects the whole it's financing». Further, the Football Association of country B added that "Club A and Club A2 are different legal entities».

In view of the foregoing and in particular the chronology of events, the DRC held that, at the moment that the Respondent was in the process of registering the player, as well as when it entered the transfer instruction into the TMS, it was only in possession of the player passport 1 which it received from the Football Association of country B and according to which the player had only been registered with Club $\mathrm{F}$ and $\mathrm{Club} \mathrm{H}$.

In light of all the foregoing, the DRC concluded that the Respondent could rely in good faith on the player passport 1 and reasonably assume that the player had not been trained by any other club than Club $\mathrm{F}$ and Club $\mathrm{H}$. As a result, the DRC decided to reject the Club-Claimant's claim ${ }^{32}$.

30 Decision of the Dispute Resolution Chamber passed in Zurich, Switzerland, on 2 September 2015 (0915471). URL: http://www.fifa.com/about-fifa/official-documents/governance/dispute-resolution-chamber.html (accessed: 18.07.2017).

31 Decision of the Dispute Resolution Chamber passed in Zurich, Switzerland, on 25 September 2015 (0915288). URL: http://www.fifa.com/about-fifa/official-documents/governance/dispute-resolution-chamber.html (accessed: 18.07.2017).

32 Decision of the Dispute Resolution Chamber passed in Zurich, Switzerland, on 25 September 2015 (0915288). URL: http://www.fifa.com/about-fifa/official-documents/governance/dispute-resolutionchamber.html (accessed: 18.07.2017). 
Analogically, the DRC considered that the Club-Respondent had not presented any conclusive documentary evidence which could corroborate the absence of a previous record of the player and therefore could not conclude that the Respondent could rely in good faith and reasonably assume that the player had not been trained by the Club-Claimant ${ }^{33}$.

Thus, in the absence of any information to the contrary, the Chamber concluded that the player was registered with the Respondent for the first time as a professional before the end of his $23^{\text {rd }}$ birthday and that, therefore, in principle training compensation is due.

\section{More than two years had elapsed since the event giving rise to the dispute?}

In this context, the DRC underscored that, in the documentation the Club-Claimant provided in support of its claim, it is established that the player was allegedly already a professional with Club-Respondent on 7 March 2012. On account of the above considerations, the DRC concluded that the Claimant lodged its claim on 6 October 2014 only, this is, more than two years had elapsed since the event giving rise to the dispute (i.e. on 7 April 2012 at the latest) and, thus, decided that the claim of the Claimant is inadmissible ${ }^{34}$.

On other case DRC reverted to the argument raised by the Respondent, according to which the claim of the Claimant would be time-barred since the Respondent was only notified about the relevant claim in July $2015^{35}$. In this regard, DRC referred to art. 25 par. 5 of the FIFA Regulations, according to which, inter alia, the Dispute Resolution Chamber shall not hear any case subject to the said Regulations if more than two years have elapsed since the event giving rise to the dispute. The present claim having been lodged in front of the DRC on 24 July 2014, and the registration of the player with the Respondent having occurred on 28 August 2012, the DRC had to reject the respective argument brought up by the Respondent and thus confirmed that the present petition was lodged in front of the DRC within said two-year period of time. In this regard, the DRC wished to recall that, according to art. 3 par. 1 and 2 of Annex 4 of the FIFA Regulations, the deadline for the payment of training compensation is 30 days following the registration of the professional with the new association. Hence, the event giving rise to the dispute is the non-payment of training compensation 30 days after 28 August 2012. The matter is, thus, not time-barred by the statute of limitations in accordance with art. 25 par. 5 of the FIFA Regulations.

\section{New Club's argument that it constituted a different entity from the Club-Respondent which liable to pay training compensation?}

The DRC referred to previous decisions of FIFA's decision-making bodies related to this particular issue as well as to the CAS Award 2013/A/3425 which mutatis mutandis can be applied to the present matter. Indeed, in said Award, CAS, while confirming a previ-

${ }^{33}$ Decision of the Dispute Resolution Chamber passed in Zurich, Switzerland, on 17 December 2015 (12150757-e). URL: http://www.fifa.com/about-fifa/official-documents/governance/dispute-resolutionchamber.html (accessed: 18.07.2017).

${ }^{34}$ Decision of the Dispute Resolution Chamber passed in Zurich, Switzerland, on 25 September 2015 (09151620-e). URL: http://www.fifa.com/about-fifa/official-documents/governance/dispute-resolutionchamber.html (accessed: 18.07.2017).

35 Decision of the Dispute Resolution Chamber passed in Zurich, Switzerland, on 26 November 2015 (11151021-e). URL: http://www.fifa.com/about-fifa/official-documents/governance/dispute-resolutionchamber.html (accessed: 18.07.2017). 
ous decision of the Players' Status Committee of FIFA, established that a club is a sporting entity identifiable by itself, which is formed by a combined set of elements that constitute its image ${ }^{36}$.

In particular, the DRC fully adopted the reasoning of the Sole Arbitrator in the aforementioned Award that reads as follows: «The Sole Arbitrator highlights that the decisions that had dealt with the question of the succession of a sporting club in front of the CAS ${ }^{37}$ and in front of FIFA's decision-making bodies, have established that, on the one side, a club is a sporting entity identifiable by itself that, as a general rule, transcends the legal entities which operate it. Thus, the obligations acquired by any of the entities in charge of its administration in relation with its activity must be respected; and on the other side, that the identity of a club is constituted by elements such as its name, colors, fans, history, sporting achievements, shield, trophies, stadium, roster of players, historic figures, etc. that allow it to distinguish from all the other clubs. Hence, the prevalence of the continuity and permanence in time of the sporting institution in front of the entity that manages it has been recognized, even when dealing with the change of management companies completely different from themselves» (original text in Spanish).

Having said this, the DRC focused their attention on the following facts: (1) Club G is registered at the same address as Club C; (2) the official website of Club G is XXXX; (3) the official e-mail address of Club G is XXXX; (4) Club G started to participate in the competitions organized by the Football Federation of country D, the season immediately after the season when Club C ceased to participate in the aforementioned competitions; (5) Club G started to participate in the division immediately inferior to the one in which Club $\mathrm{C}$ was participating during the 2012-13 season and finished in a position leading to relegation.

Regarding said last consideration, the DRC was eager to emphasize Club G's statement, according to which «[t] $\mathrm{t}$ he highest division the club ever participated was the second division (last season played was 2012/2013)» ${ }^{38}$. In addition, the DRC deemed of utmost importance to point out that on 30 October 2013, Club G took over the TMS account of Club C. In sum, and in consideration of the above-mentioned facts, the DRC was of the unanimous opinion that the new club's argument that it constituted a different entity from Club C cannot be upheld.

\section{Conclusion}

After analyzing the decisions of the Dispute Resolution Chamber it becomes evident, that regardless of the fact that DRC mostly pays attention to formal circumstances, which indicate the duty of the club to pay training compensation, the DRC however proceeds

${ }^{36}$ Decision of the Dispute Resolution Chamber passed in Zurich, Switzerland, on 17 December 2015 (12150569-e). URL: http://www.fifa.com/about-fifa/official-documents/governance/dispute-resolutionchamber.html (accessed: 18.07.2017); Decision of the Dispute Resolution Chamber passed in Zurich, Switzerland, on 17 December 2015 (12150733-e). URL: http://www.fifa.com/about-fifa/official-documents/governance/dispute-resolution-chamber.html (accessed: 18.07.2017).

37 Arbitration CAS 2007/A/1355 FC Politehnica Timisoara SA v. FIFA \& Romanian Football Federation (RFF) \& Politehnica Stintia 1921 Timisoara Invest SA, award of 25 April 2008; TAS 2011/A/2614; Arbitration CAS 2011/A/2646 Club Rangers de Talca v. Fédération Internationale de Football Association (FIFA), award of 30 April 2012; TAS 2012/A/2778. URL: http://jurisprudence.tas-cas.org/Search/results. aspxk=Title\%3D'508A151D-795A-4840-A64D-4907061DA103' (accessed: 18.07.2017).

38 Decision of the Dispute Resolution Chamber passed in Zurich, Switzerland, on 17 December 2015 (12150569-e). URL: http://www.fifa.com/about-fifa/official-documents/governance/dispute-resolutionchamber.html (accessed: 18.07.2017). 
from the aim of training compensation. In many of its' considerations the DRC noted that all training clubs shall, in principle be rewarded for their efforts invested in training young players ${ }^{39}$.

The DRC also mentioned many times, that even the nature of player's registration with a club claiming training compensation is irrelevant with respect to the question as to whether such club would be entitled to receive training compensation.

The main issue for the clubs is whether or not the Dispute Resolution Chamber accepts the arguments that are not based on formal circumstances of the article 20 and 21 of the FIFA Regulations, but on general principles and logic. As we can see from the facts of the cases claimants usually pay attention to formal circumstances as they provides the possibility to make training compensation payable as clubs claiming training compensation in fact contributed to the training and education for the period set by the FIFA in its' Regulations.

It is quite obvious that respondents always try to avoid paying training compensation or to at least diminish the amount of the compensation. This is why they either argue that opposing party provides false argumentation, that is not confirmed in writing or they disagree on the exact amount of training compensation to which the adversary is entitled.

Before starting analyzing the specific arguments and provisions in the decisions of the DRC we should say about the general principles and fundamental ideas and lines that the Dispute Resolution Chamber mentions in its' decisions. First of all, all clubs which have in fact contributed to the training and education of a player as from the age of 12 are, in principle, entitled to training compensation for the timeframe that the player was effectively trained by them ${ }^{40}$. Secondly, the nature of the player's registration with a club claiming training compensation is in fact irrelevant with respect to the question as to whether such club would be entitled to receive training compensation for the period of time that the player was effectively trained by that club ${ }^{41}$. Thirdly, the DRC emphasized that in the following considerations it will refer only to the facts, arguments and documentary evidence which it considered pertinent for the assessment of the matter at hand ${ }^{42}$.

As we can see from the analyzes of the Dispute Resolution Chamber's decisions the DRC refers only to the facts that are disputed between the parties. When it is undisputed between the parties that the claimant is entitled to receive training compensation from the Respondent, but the parties disagree on the exact amount of training compensation to which the claimant is entitled, the DRC takes into consideration all the arguments of the parties to find out the educating and training period in order to calculate the training compensation entitled to the claimant. It is evident that clubs will try to diminish the amount of the training compensation with the reference to the fact that player's training

39 Decision of the Dispute Resolution Chamber passed in Zurich, Switzerland, on 24 April 2015 (0415015-e). URL: http://www.fifa.com/about-fifa/official-documents/governance/dispute-resolutionchamber.html (accessed: 18.07.2017).

40 Decision of the Dispute Resolution Chamber passed in Zurich, Switzerland, on 10 February 2015 (0215699). URL: http://www.fifa.com/about-fifa/official-documents/governance/dispute-resolution-chamber.html (accessed: 18.07.2017).

${ }^{41}$ Decision of the Dispute Resolution Chamber passed in Zurich, Switzerland, on 10 February 2015 (0215699). URL: http://www.fifa.com/about-fifa/official-documents/governance/dispute-resolution-chamber.html (accessed: 18.07.2017).

42 Decision of the Dispute Resolution Chamber passed in Zurich, Switzerland, on 21 January 2015 (01152032). URL: http://www.fifa.com/about-fifa/official-documents/governance/dispute-resolutionchamber.html (accessed: 18.07.2017). 
was already completed at the exact time regardless of the submitted documentation of the claimant. The possible way to prove it is to draw attention to the number of games completed by the player or to mention the particular position of the player in some games. The DRC referring to the documentation submitted by the Respondent can either acknowledge or reject the mentioned arguments. On the question of the position of the payer in particular game, the DRC outlines that neither the games for the National Team of Country nor the fact that the player was named a captain of such team on one occasion can be considered as the proof of the idea that the player's training was already completed at that time. The DRC mentions that it will rather be an indication of the player's talent, skills and level of training, but that such fact is not conclusive to establish that the player had completed his training before his $21^{\text {st }}$ birthday ${ }^{43}$.

The other fact that respondent club tried to use in order to avoid paying training compensation is the scholarship agreement between the player and the respondent. Regardless of the fact whether the player was registered with the respondent as a professional, respondent argued that the player was not earning more than the expenses incurred for his football activity under the scholarship agreement and can, therefore, not be considered a professional player in light of art. 2 of the FIFA Regulations on the Status and Transfer of Players. On the one hand, the respondent held it right arguing that the status of the player depends on the amount of money paid for his footballing activity, not only for the expenses he effectively incurs and that the legal nature or the designation of the contract is of no relevance in this regard ${ }^{44}$. But on the other hand, the respondent in the matter at hand didn't manage to proof that the player was in fact paid more for the expenses he effectively incurred than for his footballing activity. And as the DRC's well-established jurisprudence shows and according to the art. 12 par. 3 of FIFA Procedural Rules any party claiming a right on the basis of an alleged fact shall carry the burden of proof, the DRC concluded that the respondent is obliged to pay training compensation.

Another argument that respondents referred to avoid the high cost of the training compensation was the fact that the player's transfer to the claimant was a loan and that the claimant failed to prove the existence of loan agreement. Clubs also pointed out that when the claimant wasn't the player's last club, as after the expiry of the loan the professional returned to his club of origin, it was not entitled to claim training compensation. However, as we have already mentioned the Dispute Resolution Chamber noted that the nature of the player's registration is irrelevant and it is, in principle, important whether or not the club claiming training compensation has contributed to the training and education of the player $^{45}$.

${ }^{43}$ Decision of the Dispute Resolution Chamber passed in Zurich, Switzerland, on 21 January 2015 (01152032). URL: http://www.fifa.com/about-fifa/official-documents/governance/dispute-resolutionchamber.html (accessed: 18.07.2017).

${ }^{44}$ Decision of the Dispute Resolution Chamber passed in Zurich, Switzerland, on 21 January 2015 (01152727). URL: http://www.fifa.com/about-fifa/official-documents/governance/dispute-resolutionchamber.html (accessed: 18.07.2017).

${ }^{45}$ Decision of the Dispute Resolution Chamber passed in Zurich, Switzerland, on 10 February 2015 (0215699). URL: http://www.fifa.com/about-fifa/official-documents/governance/dispute-resolution-chamber.html (accessed: 18.07.2017); Decision of the Dispute Resolution Chamber passed in Zurich, Switzerland, on 10 February 2015 (02153411). URL: http://www.fifa.com/about-fifa/official-documents/governance/dispute-resolution-chamber.html (accessed: 18.07.2017); Decision of the Dispute Resolution Chamber passed in Zurich, Switzerland, on 10 February 2015 (02153392). URL: http://www.fifa.com/about-fifa/official-documents/governance/dispute-resolution-chamber.html (accessed: 18.07.2017). 
In most of the cases the Dispute Resolution Chamber accepted or partially accepted the claimant's claim. According to the aforementioned considerations for the Chamber it is rather important when the facts of the case meet the formal circumstances, that are described in the art. 20 and 21 of the FIFA Regulations. As the claimant usually draw the attention to such kind of circumstances it is expected that the DRC will confirm the claimant's arguments and refute the considerations of the respondent. However, during the analysis of the DRC's decisions we met a case, when the claim of the claimant was rejected, because the claimant hadn't complied with the prerequisites of art. 6 par. 3 of Annexe 4 of the Regulations in order to be entitled to training compensation ${ }^{46}$. This practice confirms the idea that despite the DRC always maintains the general principals and lines it, however, prefers a formal approach.

In 2016 the Dispute Resolution Chamber in some of its' decisions held that if the club is not the party of other clubs' agreements, the consequence out of this agreement do not affect that club. In the decisions made by the DRC in 2015 we can see the proof of this statement. For example, the clubs can agree upon the transfer of the player noting that "the fee paid is including all solidarity payment and training compensation according to national and international rules» ${ }^{47}$. The DRC concurs that training compensation can be included in the transfer fee if the two clubs expressly agree upon it. In this context, the DRC judge acknowledged that the respondent agreed upon a transfer fee with other club which included training compensation. However, as the claimant was not a party to this transfer agreement, the consequences out of this agreement do not affect the claimant. Therefore, the FIFA Regulations have to be applied and the claimant is entitled to receive training compensation. The DRC also emphasizes that the consequences out of transfer agreement do not affect the claimant, when the former club waives its' right to receive training compensation as the claimant is not the party of this agreement as well ${ }^{48}$.

The other reason why respondents may try to rebut the claim of the claimant is that no training compensation is due since «In these case no transfer had been made, there was no transfer contract between [the Respondent] and [the Claimant], and the player signed for [the Respondent] as a free agent...» ${ }^{49}$. But according to one of the main principles of the Dispute Resolution Chamber in terms of the training compensation, it is payable, as a general rule, for training incurred between the ages of 12 and 21 when a player is registered for the first time as a professional before the end of the season of the player's $23^{\text {rd }}$ birthday or when a professional is transferred between clubs of two different associations, whether during or at the end of his contract, before the end of the season of the player's $23^{\text {rd }}$ birthday. And as the professional was effectively trained by the claimant the training compensation is payable.

${ }^{46}$ Decision of the Dispute Resolution Chamber passed in Zurich, Switzerland, on 12 March 2015 (0315392). URL: http://www.fifa.com/about-fifa/official-documents/governance/dispute-resolution-chamber.html (accessed: 18.07.2017).

47 Decision of the Dispute Resolution Chamber passed in Zurich, Switzerland, on 24 April 2015 (0415015-e). URL: http://www.fifa.com/about-fifa/official-documents/governance/dispute-resolutionchamber.html (accessed: 18.07.2017).

48 Decision of the Dispute Resolution Chamber passed in Zurich, Switzerland, on 24 April 2015 (0415255). URL: http://www.fifa.com/about-fifa/official-documents/governance/dispute-resolution-chamber.html (accessed: 18.07.2017).

49 Decision of the Dispute Resolution Chamber passed in Zurich, Switzerland, on 10 April 2015 (0415928). URL: http://www.fifa.com/about-fifa/official-documents/governance/dispute-resolution-chamber.html (accessed: 18.07.2017). 
All things considered, there are many possible way to avoid paying training compensation, however, almost none of them worked in the aforementioned cases. The main reason why most of the respondents failed in their argumentation is that they ignored basic rules, principles and formal circumstances. There is a paucity of the DRC's cases, that ended up with the success of the respondent, however, those of respondents who managed to win an argument with the opponent referred to the procedural rules or formal violations. This again proves the statement that the DRC mostly takes into consideration confirmed facts and prefers formal approach.

As to the calculation of the training compensation, it is important to note that the Dispute Resolution Chamber undisputedly uses one general principle. The DRC often refers to art. 5 par. 1 and par. 2 of Annexe 4 of the FIFA Regulations, which stipulate that as a general rule, to calculate the training compensation due to a player's former club, it is necessary to take the costs that would have been incurred by the new club if it had trained the player itself ${ }^{50}$. The present mechanism of the training compensation costs was detailed in Andrew Smith`s two articles [3; 4].

Entering the substance of the matter, the members of the Dispute Resolution Chamber start by acknowledging the mentioned facts of the case as well as the documentation on file. Moreover, the DRC in its' considerations refers only to the facts, arguments and documentary evidence which it considered pertinent for the assessment of the matter at hand $^{51}$. It is important to mention, that according to the art. 12 par. 3 of FIFA Procedural Rules any party claiming a right on the basis of an alleged fact shall carry the burden of proof.

All in all, we can definitely say that the Dispute Resolution Chamber has its' wellestablished jurisprudence [5] and a clear mechanism in accordance with which the DRC settles disputes between the clubs in terms of the matter at hand.

\section{References}

1. John Shea. Football player contracts - waiving training compensation. LawInSport. Available at: https://www.lawinsport.com/blog/john-shea/item/football-player-contracts-waiving-training-compensati on?highlight=WyJ0cmFpbmluZyIsInRyYWluaW5nJyIsIid0cmFpbmluZyIsInRyYWluaW5nJywiLCJjb21wZW5zYXRpb24iLCJjb21wZW5zYXRpb24nLCIsImNvbXBlbnNhdGlvbiciLCJ0cmFpbmluZyBjb21wZW5zYXRpb24iXQ== (accessed: 02.08.2017).

2. Lloyd Thomas. The on-going football dispute over training compensationand player loans II: Dundee UTD -v- Club Athletico Velez. LawInSport. Available at: https://www.lawinsport.com/blog/ squire-patton-boggs/item/the-on-going-football-dispute-over-training-compensation-and-player-loans-iidundee-utd-v-club-athletico-velez?highlight=WyJ0cmFpbmluZyIsInRyYWluaW5nJyIsIid0cmFpbmluZyIsInRyYWluaW5nJywiLCJjb21wZW5zYXRpb24iLCJjb21wZW5zYXRpb24nLCIsImNvbXBlbnNhdGlvbiciLCJ0cmFpbmluZyBjb21wZW5zYXRpb24iXQ== (accessed: 02.08.2017).

3. Andrew Smith. A guide to training compensation and solidarity payments in football. LawInSport. Available at: https://www.lawinsport.com/articles/item/a-guide-to-training-compensation-and-solidaritypayments-in-football?highlight=WyJ0 cmFpbmluZyIsInRyYWluaW5nJyIsIid0cmFpbmluZyIsInRyYWluaW5nJywiLCJjb21wZW5zYXRpb24iLCJjb21wZW5zYXRpb24nLCIsImNvbXBlbnNhdGlvbiciLCJ0cmFpbmluZyBjb21wZW5zYXRpb24iXQ== (accessed: 02.08.2017).

50 Decision of the Dispute Resolution Chamber passed in Zurich, Switzerland, on 24 April 2015 (0415015-e). URL: http://www.fifa.com/about-fifa/official-documents/governance/dispute-resolutionchamber.html (accessed: 18.07.2017).

${ }^{51}$ Decision of the Dispute Resolution Chamber passed in Zurich, Switzerland, on 21 January 2015 (01152032). URL: http://www.fifa.com/about-fifa/official-documents/governance/dispute-resolutionchamber.html (accessed: 18.07.2017). 
4. Andrew Smith. A legal guide to training compensation in football under the FIFA Regulations. LawInSport. Available at: https://www.lawinsport.com/articles/item/a-legal-guide-to-trainingcompensation-in-football-under-the-fifa-regulations?highlight=WyJ0cmFpbmluZyIsInRyYWluaW5nJy IsIid0cmFpbmluZyIsInRyYWluaW5nJywiLCJjb21wZW5zYXRpb24iLCJjb21wZW5zYXRpb24nLCIsImNvbXBlbnNhdGlvbiciLCJ0cmFpbmluZyBjb21wZW5zYXRpb24iXQ== (accessed: 02.08.2017).

5. Aroian M. Iu., Vasil'ev I. A. Osnovnye problemy osushchestvleniia klubami kompensatsii za podgotovku i obuchenie futbolista: obzor praktiki Palaty FIFA po razresheniiu sporov za $2016 \mathrm{~g}$. [The main problems of football club's training compensation mechanism: the Dispute Resolution Chamber 2016 practices review]. Peterburgskii Iurist [Petersburg Lawyer], 2017, no. 2. (In Russian)

For citation: Vasiliev I. A., Aroyan M. U. The main issues on paying the training compensation in FIFA Dispute Resolution Chamber's cases 2015. Vestnik SPbSU. Law, 2017, vol. 8, issue 4, pp. 479-499.

https://doi.org/10.21638/11701/spbu14.2017.410

Received: 11.06 .2017

Accepted: 29.08.2017 